\title{
Impact of learning, exclusively online, during a pandemic
}

\section{Benlounissi Aïcha}

Higher National School of Biotechnology “Taoufik Khaznadar”, Constantine, Algeria

Received: 10 Oct 2020; Received in revised form: 12 Nov 2020; Accepted: 14 Nov 2020; Available online: 17 Nov 2020

\begin{abstract}
This study focuses on the use of a distance learning platform to deliver on-line classes, during the second semester of the 2019-2020 academic year, in a higher school in an urban area.

The study is carried out mainly with, the aim of understanding on the perception and admissibility or not of distant teaching, in its entirety, by students accustomed to on-site teaching. The data were collected by the course activities reports and a questionnaire survey carried out among the 207 students registered on a distance learning platform; the results obtained allow to deduce the interest of the learning environment and of the interactions between actors during teaching practices using technological tools in a distant teaching process.
\end{abstract}

Keywords — Learning, Distance learning platform, Pandemic, Acceptability, behaviour.

\section{INTRODUCTION}

Put at the service of pedagogies, Information and Communication Technologies (ICT) are learning and teaching tools, allowing the different actors to communicate, interact, share and collaborate for a defined purpose which is learning. In this sense, several distance education platforms have been designed to facilitate distance learning. The Moodle platform is one of the free learning environments, developed on pedagogical principles, which allow to create communities united and oriented around content and learning activities.

Integrating ICT in education precisely at the university level has been a success in several countries, knowing that their adoption required a great will and a contribution of all the specialists of education, in our country, even if the ICT have taken place in higher education for more than a decade, but many efforts are still to be made to instill students mastering ICT and its various uses in order to integrate them meaningfully and autonomously into their learning process (Brahami, 2015).

ICT in teaching, help the trainer to facilitate the work of the learner during the progressive construction of his knowledge, know-how and personal skills.

\section{OBJECTIVES}

This work reports the results of a study carried out with 207 students registered on a distance learning platform, the objective of which is to identify and understand the activities of students in the course over a period of 4 months, in pandemic context, in order to establish whether or not, it may be possible to provide a completely distance learning.

\section{METHODOLOGY}

In order to understand the behavior of students vis-à-vis totally distant teaching and to identify their interactions with their teacher and their peers, this study was based on data collected through, reports of course activities and a questionnaire survey carried out among the 207 students enrolled in the course.

\subsection{Participants}

The students who were the subject of this study are engineering students registered on a distance learning platform, in a course that is part of their university course, usually followed within the premises of their higher school. During the pandemic period, total home confinement has forced the institution to switch to a totally distance education. 
The sample is composed of $15.9 \%$ men and $84 \%$ women, $98 \%$ of whom are 20 years old.

\subsection{Collection of data}

Data collection was carried out by two methods:

1. Monitoring of course activities for students registered on the Moodle platform,

2. Questionnaire survey of these students.

107 students answered to the online questionnaire within the set deadlines.

The data collected was subjected to a graphical analysis.

\section{RESULTS AND DISCUSSION}

\subsection{Follow-up of course activities}

\subsubsection{Course consultation}

The number of students registered at the beginning of the semester of the current year was 185 , the consultation rate of chapter 1 at the level of the course, document resources and video resources was 46\%, $17 \%$ and 20, 54\% respectively, for chapter 2 (courses, document resources and video resources) the consultation was $47 \%, 13.51 \%$ and $12.85 \%$ respectively, $1.62 \%$ of users had used the forum to interact with their peers (fig. 1).

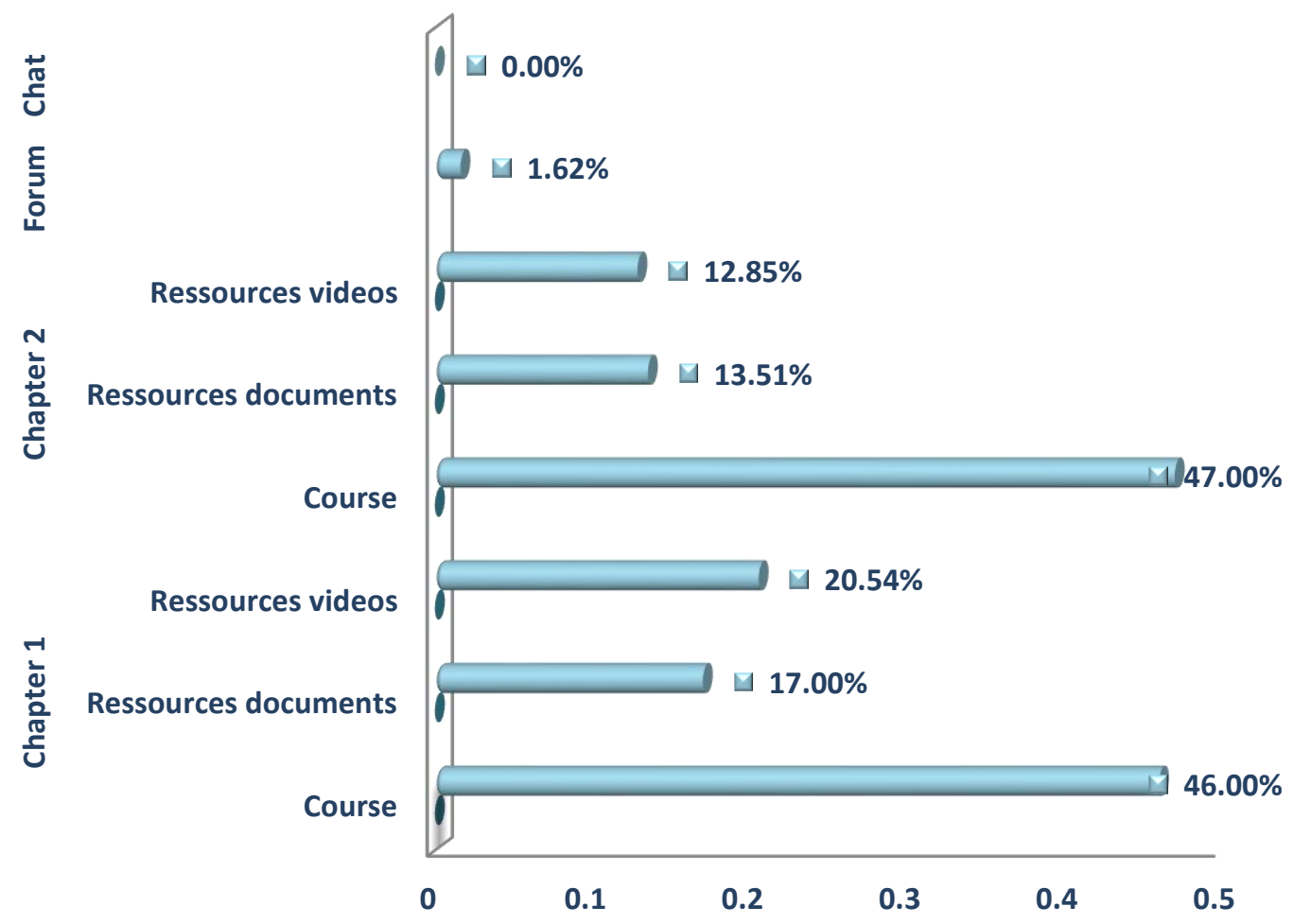

Fig. 1: Course participation rate at the start of semester 2

The average participation in the course during this period is acceptable, because the beginning of the second semester, in our institution, is concomitant with the final exams of the first semester, which does not allow students to properly follow all the courses during this period. For several years this programming has had no negative effect on the rest of the courses.

\subsubsection{Participation in the course during the period of total home confinement}

From the start of the confinement, following the SARSCoV-2 pandemic, the students were placed in a situation of forced distance learning, which had forced them to use the teaching platform in order to consult the course and resolve all the situational problems.

The course monitoring report established the rates of students who participated in each chapter over a 4-month period.

It was found that $82.12 \%, 37.68 \% 49.76 \%$ of the students had consulted the course, the document resources and the video resources of chapter 4 respectively against $46.54 \%$, $18.84 \%$ and $18.35 \%$ for the course, document resources and video resources of chapter 6 respectively (fig. 2). 


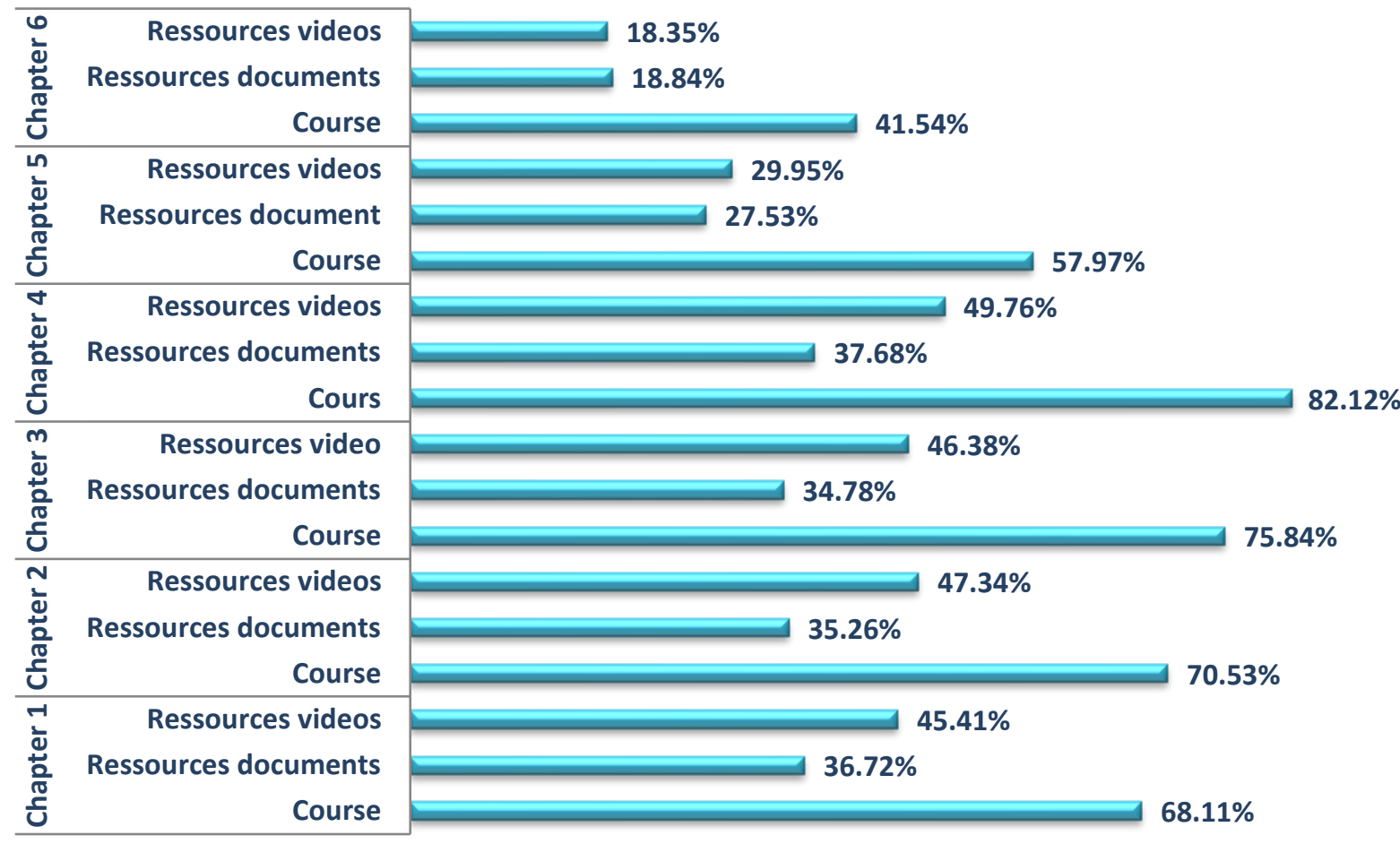

Fig. 2: Course participation rate

Figure 2 shows a $40.58 \%$ drop in participation rate between the fourth and sixth chapter, which can be explained by the confinement period due to SARS-CoV-2 which lasted more than 3 months, and which had a negative effect on student motivation.

Indeed, the questionnaire survey revealed that $61.72 \%$ believe they are not psychologically ready to follow a totally distant education; $71.60 \%$ have trouble getting organized and 60.49 think they need motivation or help to follow the course properly.

On the other hand, $71.60 \%$ felt that they needed to keep in touch with their peers and their teacher in order to follow the course properly.

The work carried out by Lian-Ko-Yao, Z. (2017) has shown that students' motivation is closely linked to their school environment and is co-constructed thanks to direct relationships with their peers or their teacher, hence the notion of co-constructivism of knowledge. The stress of students during a pandemic not being studied did not allow us to compare the results obtained in this study with other works, but the study carried out by Bégin-Caouette, O. (2009) on the effects positive and negative stress on learning reports that a lot of stress reduces learner performance.

In addition, it should be noted that the lack of activity during this period could be at the origin of this demotivation, because according to the work of Trudeau, F. and Shephard, RJ (2008) physical activity would have a positive effect. on learning and therefore on certain determinants of academic success, a practice which seems not to be easy to maintain during this period of confinement for $90 \%$ of the students in this study.

\subsubsection{Participation in group activities}

The course monitoring report also made it possible to establish the participation rates in group activities, carried out using collaboration tools: forum, chat, glossary, wiki and a videoconferencing tool, $60.86 \%$ of the students used the chat to carry out group work, $45.89 \%, 34.78 \%, 19.81 \%$ used the forum, the glossary and the videoconference respectively (fig. 3). 


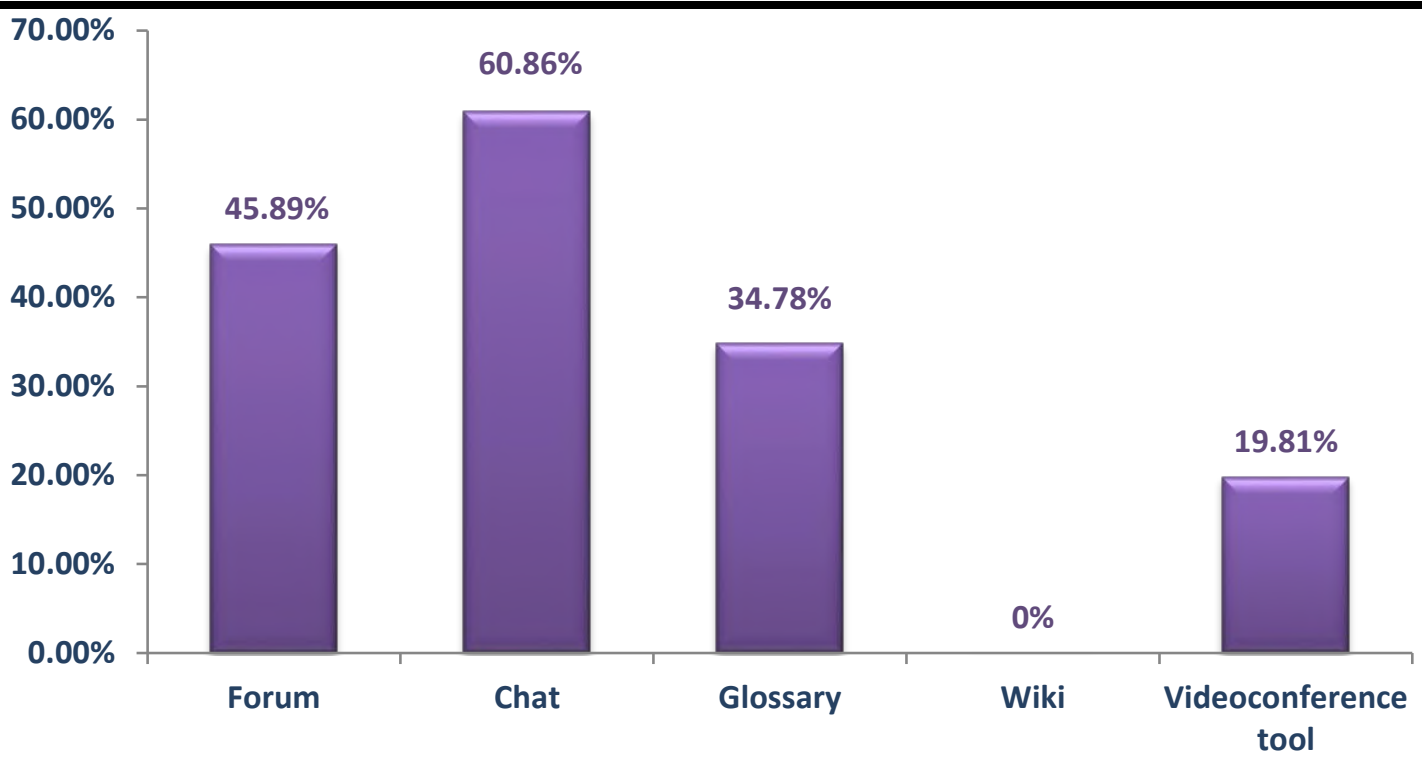

Fig. 3: Participation rate in group activities

Of these students, those using chat to interact with their peers were simultaneously using the other three tools, namely, the forum, the glossary and the video conferencing tool. None of them had participated in the Wiki activity.

\subsubsection{Participation in complementary activities}

In order to better assimilate the online course for the 207 students registered on the distance learning platform, additional activities were developed such as exercises outside tutorials, synchronous lesson sessions and synchronous tutorial sessions in addition an optional part complementary to the course.

For this part of the course, the activity report found that only $5.79 \%$ of the students had solved the additional exercises compared to $76.33 \%$ who were interested in the solved exercises made available to them (fig. 4).

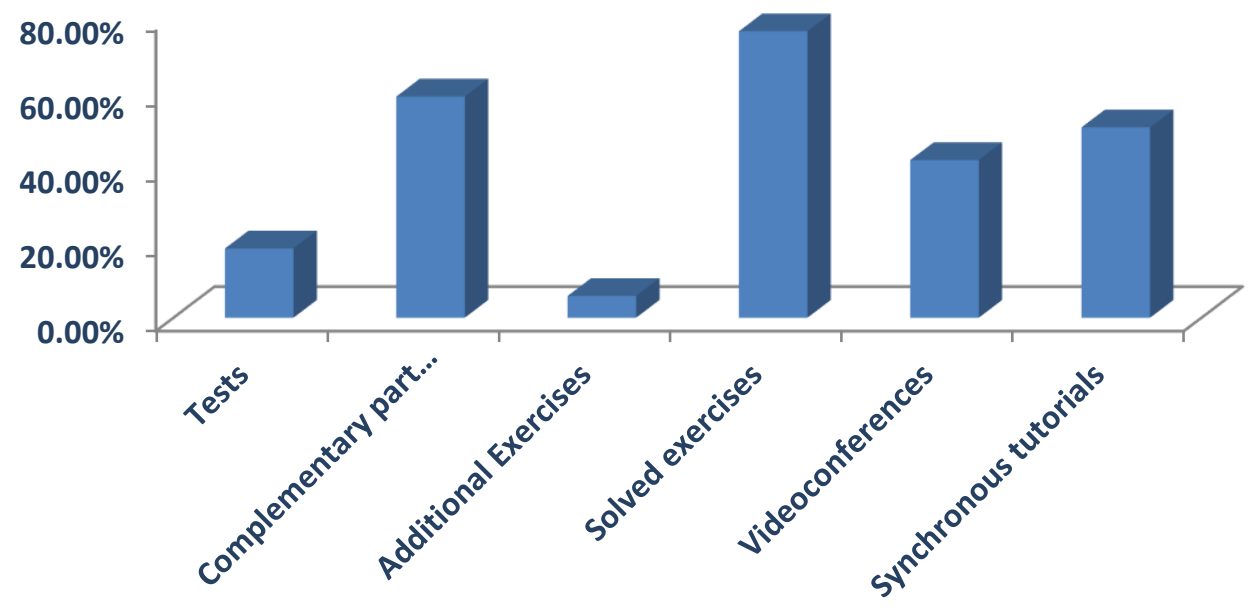

Fig. 4: Participation rate in complementary activities

$42 \%$ and $50.72 \%$ of students attended lectures and synchronous tutorials respectively. $58.93 \%$ of them had expressed an interest in the additional part of the course but only $18.44 \%$ had taken the prior learning assessment tests. 


\subsubsection{Survey}

The analysis of the questionnaire carried out in parallel, made it possible to put the point on the difficulties encountered by the students during the follow-up of the courses online knowing that $94.39 \%$ of these studentengineers had, at their home, an internet connection. , of which $54.20 \%$ was broadband.

When asked about the number of times students viewed the course, $37 \%$ of them reported accessing the platform twice a week.

By questioning them about the means of collaboration made available to them and the frequency of their use, recalling that their implementation avoids the isolation of students during this period of pandemic, $44.44 \%$ of them, say they use the forum to ask their questions. Indeed, Figure 3 shows that $45.89 \%$ of the students used the forum, which means that $1.5 \%$ of the users of the forum did not take part in the survey.

As a reminder, the course forum is accessible to all registered students as well as to their teacher, each of them can ask questions, answer and add resources if necessary, this tool helps clarify points relating to the course.

The study by Benabid-Zarrouk (2012) showed that more students who participate in forums succeed, even though the vast majority of them do not use it. According to Henri et al., (2007), the forum is also an educational means that would empower students and set up a form of distributed cognition, on the other hand Quanquin (2013) states that the integration of forum in different types of education could significantly modify the pedagogical approach.

The testimony on the use of the chat shared by Rodet (2003) highlighted the usefulness of a chat room in strengthening the identity of a group of learners, who could easily transform this tool into media to support learning through collective and reflective practices, something that was not observed in our study.

\section{CONCLUSION}

The work carried out made it possible to observe the behavior of the students on a distance learning platform but did not allow the teacher to observe this behavior in real time, even if the course sessions synchronized via the videoconferencing tool was there to try to better understand it.

The results show that the virtual presence cannot replace the physical presence of the teacher or the student because this presence would have created the human bonds which these students needed to feel confident in order to build their knowledge.

In face-to-face, the teacher can capture the attention of the students and put them in a learning situation in a group dynamic, but the distance created by the pandemic has stimulated reflexes in the students to which they were not used and their teacher had difficulty identifying initially, since the interruption of the current academic year developed in them an inability to study in an environment which was not familiar.

Thus, the perception of distance learning, as well as the tools used to provide it, must evolve in order to allow better management of learning in times of unforeseen crises.

\section{REFERENCES}

[1] Bégin-Caouette, O. (2009). Les effets positifs et négatifs du stress sur l'apprentissage, 1-10. http://olivierbegincaouette.yolasite.com/resources/stress.pd $\underline{f}$

[2] Ben Abid-Zarrouk, S. (2012). "Les échanges sur les forums et la réussite en enseignement en ligne »? ", Les dossiers des sciences de l'éducation. https://doi.org/10.4000/dse.524

[3] Brahami, M.A. (2015). Les TIC dans l'éducation en Algérie [Thèse de Doctorat en Sciences Commerciales]. Université d'Oran. Algérie.

[4] Henri, F. Compte, C. et Charlier, B. (2007). La scénarisation pédagogique dans tous ses débats...Revue internationale des technologies en pédagogie universitaire, 4(2), 13-24.

[5] Lian-Ko-Yao, Z. (2017). L'effet maître: L'influence de l'implication professionnelle de l'enseignant sur la mobilisation scolaire de l'élève [Mémoire de Master, École Supérieure du Professorat et de l'Éducation, Académie de la réunion]. https://dumas.ccsd.cnrs.fr/dumas02469102/document

[6] Quanquin, V. (2013). Le forum de discussion comme outil complémentaire d'apprentissage: aide à distance à la rédaction du rapport de stage, Cestis, Caen, France (hal00805833).

[7] Rodet, J. (2003). Le clavardage (chat), média de support à l'apprentissage ? Distances et savoirs, 3(1), 399-406.

[8] Trudeau, F. et Shephard, R.J. (2008). Physical education, school physical activity, school sports and academic performance. International Journal of Behavioral Nutrition $\begin{array}{llll}\text { and Physical Activity, } & \text { 5(1), }\end{array}$ https://doi.org/10.1186/1479-5868-5-10 